\title{
We Are All in This Together
}

Joy Richards, PhD

Vice President, Professional Practice \& Chief Nursing Executive, The Scarborough Hospital

In these times, it's some comfort to know we are all in this together. The economic environment in the provinces, in Canada and in the United States is challenging for governments and healthcare budgets across North America and beyond.

Many of us are feeling isolated as travel and education budgets are restricted while patient flow demands, H1N1 and the pressures of work increase. This is a time for us, the chief executive nurses, to take a leadership position in our organizations. Two years ago we reviewed the strategic plan of the Academy of Canadian Executive Nurses (ACEN). The primary foci for ACEN are to network and set policy on healthcare issues involving the nursing profession, share innovative management initiatives and discuss provincial healthcare organizational structures such as regionalization.

ACEN has had a challenging year. Many organizations placed restrictions on corporate memberships, a limitation that decreased our budget. However, we view this time as an opportunity for taking innovative measures. We have thought about the value proposition of ACEN and about our structure. Ideas currently being discussed include the following:

- Moving to an individual membership model, with the option of paying a single reduced larger membership if individuals within an organization want to amalgamate their fees.

- Annual two-day Summit and AGM.

- Quarterly webcasts to discuss current healthcare events across Canada, and to learn from one another. The webcast would feature informal presentations by nursing executives from different regions of the country. 
- Semi-annual webcast education sessions on a current nursing topic, presented by Longwoods Publishing.

- Sharing of ACEN's activities, policy statements and leadership initiatives through the Canadian Journal of Nursing Leadership.

What do you think of these ideas for ACEN's activities? Please contact us and let us know. We're inviting representative volunteers from every province to join the ACEN Executive to communicate the healthcare events and the political ramifications in their province. We also encourage you to come to the Annual General Meeting being held in Toronto the evening of February 4 and all day February 5, 2010. We will be discussing the future of ACEN as well as having a cross-country check-up in which we will find out what is happening with Saskatchewan's model of care, how ED nurses are doing outreach in long-term care homes and the impact of recent system changes in Alberta that promise "RN work will be different" - just to highlight a few issues.

Come, join our revitalized ACEN. Help us make it essential to you!

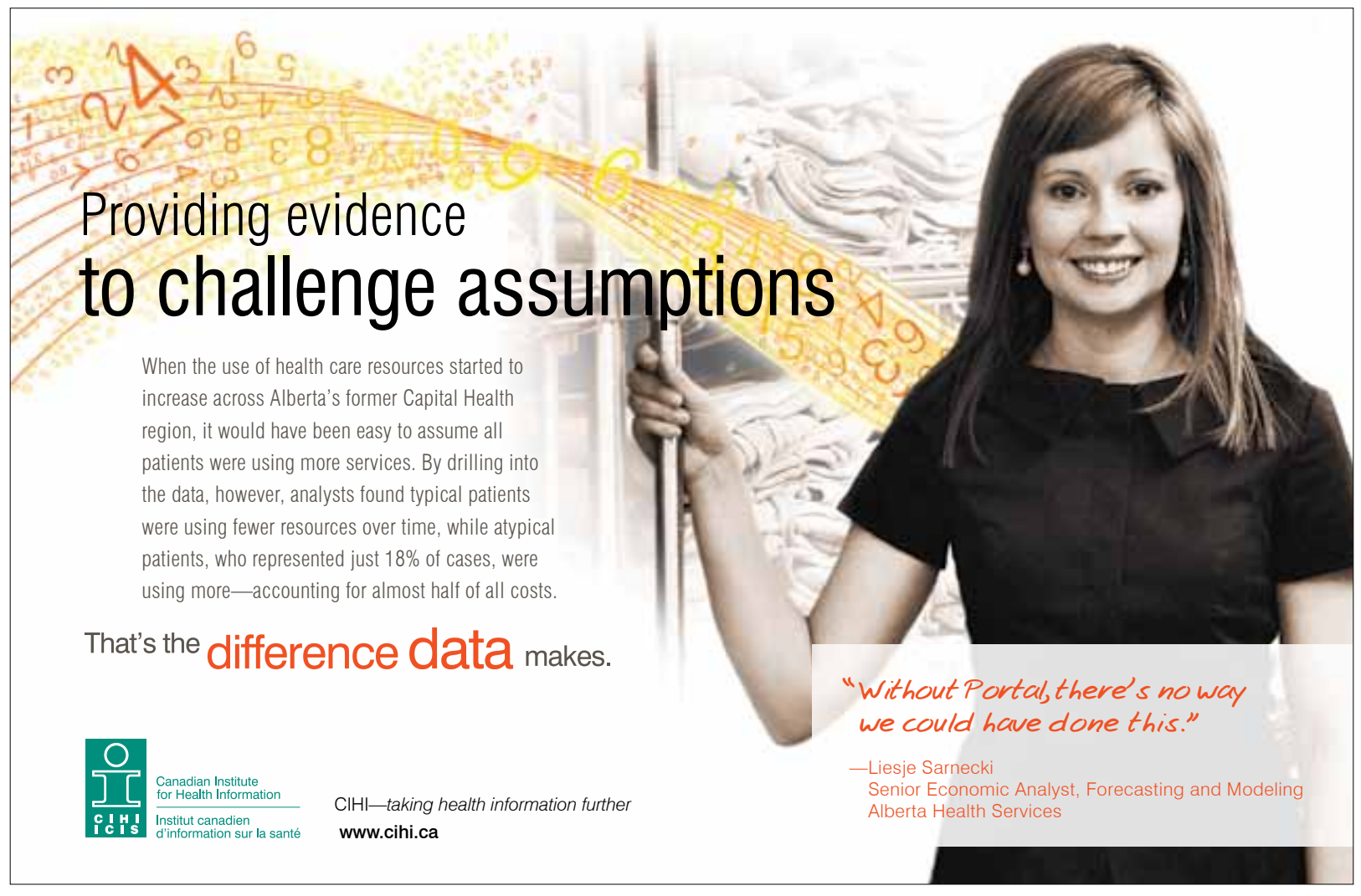

